\title{
Working with associations: A tip sheet
}

\author{
Prepared by the BIS Cooperation Committee
}

\section{Library promotion through the subject disciplines.}

\begin{abstract}
W plines other than library science can be both useful and rewarding. Attending national and regional meetings of the associations can lead to a better understanding of trends in teaching and research and possibly to better rapport between librarians and teaching faculty. Librarians also can provide information about library-related issues through presenting papers, participating in panel discussions, joining committees, displaying the BIS Bibliographic Instruction Liaison Project exhibit, and talking informally with attendees. The ACRL BIS Cooperation Committee exists to encourage such contacts. Members of the committee have composed the following list of tips for those who are interested in becoming involved in professional association activities.
\end{abstract}

\section{Getting started}

- Target your interests in an area of personal or professional expertise; an area in which you have done bibliographic instruction may be a good choice.

-Identify associations in your area of interest by looking through the Encyclopedia of Associations, and by talking to faculty members in appropriate disciplines. It may be easiest to begin with a local or regional association, and later join national level organizations.

- Read the association journal and the newsletter for reports of ongoing activities, notices of upcoming meetings, membership information, and calls for papers and proposals for sessions at upcoming meetings.

- Join the association. Most associations require membership for participation in activities and for presenting papers or sessions at meetings. Dues categories may include reduced rates for student members, new members, and individuals outside the normal association constituency.

- Attend meetings. Most associations schedule meetings at different geographic locations. Many alternate west/east/midwest meetings. Getting the flavor of the sessions is good preparation for preparing a proposal for future meetings. If possible, attend meetings with someone who already is an active member.

\section{Becoming active}

- Review the association's organizational structure and activities. Are there committees that appeal to your interests? If so, call the headquarters or communicate with association officers to find out how appointments are made. Committees that are concerned with teaching methods are frequently good choices.

- Begin an informal network of librarians who are interested in the association and attend conferences. Get-togethers at meetings can be professionally useful; in a few cases informal ties have become association-affiliated task forces.

- Contact local faculty members who belong to the association for further information on the group, or to collaborate on a program proposal.

- Find out whether the association has an exhibits area and/or poster sessions at meetings. To make arrangements to display the BI exhibit, contact the local arrangements chair for upcoming meetings. When at the booth, try to determine which aspects of library services will most appeal to association members. 


\section{Publicizing library issues}

-Write an article or letter to the editor of the association newsletter or journal about library topics that seem to be of most interest to members. Coauthor articles with members of the discipline, if possible.

- Consider targeting your efforts at a state or regional organization rather than a national group. Frequently the smaller associations are more willing to consider library-oriented proposals than the national discipline associations.

- Organize a session for a meeting. Check the newsletter for themes of upcoming meetings and the due dates for proposals; try to couch a proposal in the terminology used to describe the theme. Or, if possible, attend a meeting of the Program Committee. In most groups, it is easier to organize a complete session with several presentations than to try to join a session as an individual.

- Prepare a program proposal, tailoring it to the theme of the meeting and to the needs and interests of association members:

1. Ask for help. Members of the meeting Program Committee are sometimes helpful in clarifying criteria for accepting a proposal. Sponsorship by a particular committee or division of the association also is helpful.

2. Make it interesting. In preparing the proposal, consider the audience. Programs of interest to librarians are not necessarily of interest to individuals in other areas; try to keep library jargon at a minimum and direct attention to important issues or useful information.

3. Consider program structure and participants.
If the association consists mostly of members with academic affiliations, try a mix of small/large, university/college interests on the program.

4. Topics for papers should be timely and titles and descriptions must be interesting and provocative. Typically, programs require a moderator (who also may present a paper), two or three papers presented by their authors, and one or two commentators (one of whom may also be the moderator if he/she does not present a paper). An alternative is to have comments and questions from the audience in place of commentators, but every session should include time for audience comments if possible.

5. Have papers available so that the audience can pick them up after the presentations; use attractive visual aids and demonstrations wherever possible.

\section{The BIS Cooperation Committee}

The Committee that prepared the accompanying Tip Sheet consists of: Jane Rosenberg (chair), Council on Library Resources and OMS/ARL; Mary Ellen Kyger Davis, Central Michigan University; Elizabeth Sibley, University of California, Berkeley; John W. Collins, Boston University; David J. Norden, University of Michigan; Sandra Ready, Mankato State University; Roland Person, Southern Illinois University; and Beth Shapiro, Michigan State University.

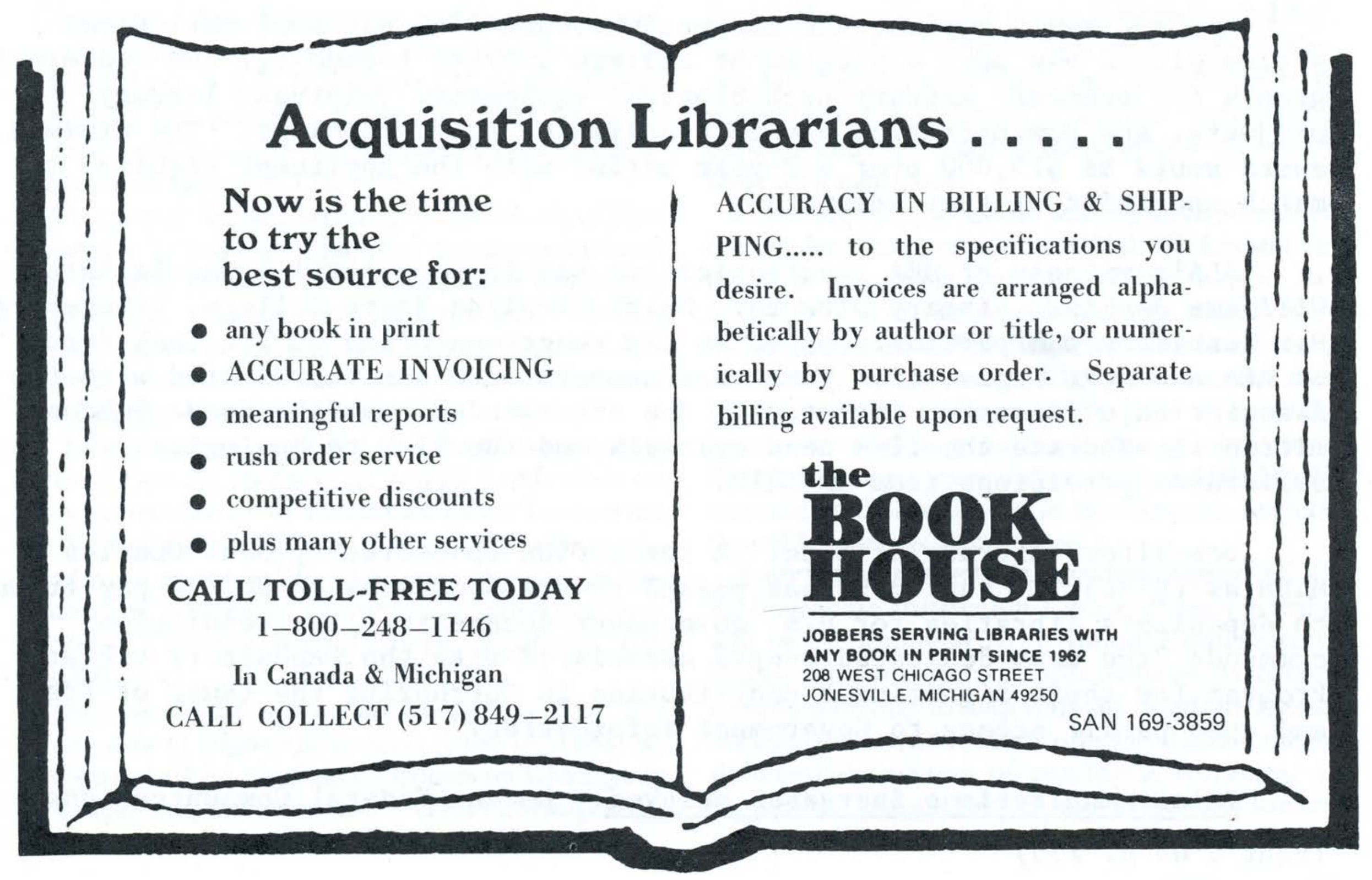

